\title{
Implementasi Produk Mikro Kreasi bagi \\ Perkembangan Usaha Kecil dan Menengah (UKM) di Era Pandemi Covid-19
}

\author{
Erika Hamim ${ }^{1}$, M. Syarif H. Elmas ${ }^{2}$, Seger Priantono ${ }^{3}$ \\ 123 Program Studi Manajemen Fakultas Ekonomi Universitas Panca Marga Probolinggo \\ Jalan Yos Sudarso No. 107 Kab. Probolinggo, Jawa Timur, 67271 \\ Correspondence: Erika Hamim (erikahamim794@gmail.com) \\ Received: 020721 - Revised: 220721 - Accepted: 080821 - Published: 280921
}

\begin{abstract}
Abstrak. Penelitian bertujuan untuk mengetahui implementasi dari Produk Mikro Kreasi bagi perkembangan usaha kecil dan menengah di Kota Probolinggo. Jenis penelitan yang digunakan adalah penelitian kualitatif dimana peneliti menggunakan teknik wawancara secara langsung terhadap nasabah pengguna produk Mikro Kreasi dan juga menggunakan jenis penelitian kuantitatif sebagai pendukung dengan menunjukkan persentase pertumbuhan usaha ditinjau dari peningkatan pendapatan sebelum dan setelah menggunakan produk ini di masa pandemi covid-19. Sampel yang di teliti adalah 10 informan. Peneliti melakukan metode pengumpulan data dokumentasi yang berasal dari sumber data primer dan sekunder berupa wawancara secara langsung dan laporan tahunan PT. Pegadaian selama periode pengamatan. Hasil penelitian menunjukkan bahwa, dari data 10 nasabah produk Ultra Mikro Kreasi PT. Pegadaian Kota Probolinggo terdapat 2 informan yang mengalami peningkatan pendapatan karena pendapatan yang didapat digunakan untuk mengembangkan usaha yaitu menambah jenis usaha untuk bertahan di masa pandemi Covid-19 dan 1 nasabah yang tidak mengalami peningkatan maupun penurunan atau dapat dikatakan pendapatannya stabil dalam perkembangan usahanya di masa pandemi Covid-19 dengan memanfaatkan sosial media dalam pemasaran produknya. Terdapat juga 7 nasabah yang tidak mengalami peningkatan pendapatan, karena pendapatan yang didapat untuk menambah peralatan usahanya.
\end{abstract}

Kata Kunci : Produk Kreasi, Usaha Kecil Menengah (UKM) Dan Covid-19.

Citation Format: Hamim, E. , Elmas, M.S.H., Priantono, S. (2021). Implementasi Produk Mikro Kreasi bagi Perkembangan Usaha Kecil dan Menengah (UKM) di Era Pandemi Covid-19. Prosiding Seminar Nasional Abdimas Ma Chung (SENAM), 2020, 216-225. 


\section{PENDAHULUAN}

Wabah Covid-19 yang sedang terjadi pada masa ini menjadi penyebab terjadinya guncangan yang mempengaruhi perekonomian negara sehingga berdampak pada instabilitas ekonomi di berbagai negara. Beberapa negara yang mengalami dampak merupakan negara yang memiliki pengaruh besar terhadap perekonomian global, salah satunya adalah Indonesia. Dampak dari adanya wabah global Covid-19 pada tahun 2020 ini juga secara signifikan memberikan catatan merah bagi pertumbuhan maupun pembangunan ekonomi di Indonesia menjadi terhambat. Hal ini berdasarkan data kementerian Koperasi dan UKM Republik Indonesia, Sensus Ekonomi dari Badan Pusat Statistik pada 2016 menunjukkan bahwa UMKM memiliki kontribusi besar terhadap perokonomian. Usaha mikro kecil menengah berkontribusi $99 \%$ dari jumlah perusahaan yang aktif di Indonesia. Peranan usaha mikro kecil menengah dalam meningkatkan ekonomi masyarakat cukup besar, dimana usaha mikro kecil menengah merupakan kegiatan usaha yang sangat diminati setelah terjadinya krisis ekonomi yang berdampak pada PHK di perusahaan besar terlebih oleh masyarakat di kota kecil seperti Kota Probolinggo.

Permasalahan yang terjadi dalam kegiatan usaha yaitu seperti kurangnya kualitas sumber daya manusia (SDM), lemahnya relasi usaha dan kurangnya dalam permodalan. Inilah yang menjadi dasar adanya lembaga keuangan yang menyediakan sistem perkreditan yang memberikan dana pinjaman. Sarana dan prasarana yang sudah diberikan oleh pemerintah dalam bidang perkreditan Lembaga Keuangan Bank dan Lembaga Keuangan Bukan Bank. Salah satu lembaga keuangan non bank yang memberikan kredit yaitu Pegadaian. PT. Pegadaian (Persero) Kota Probolinggo adalah sebuah Badan Usaha Milik Negara (BUMN) di Indonesia yang bergerak dalam bidang jasa penyaluran kredit kepada masyarakat berdasarkan hukum gadai Pegadaian memiliki prosedur dan syarat-syarat administrasi yang mudah dan bunga yang ditawarkan relatif rendah. Pegadaian memiliki beberapa macam produk Produk Kreasi merupakan kredit yang menggunakan sistem fidusia yaitu dengan jaminan BPKB tetapi kendaraan tersebut masih bisa digunakan untuk bekerja dan sewa modal yang ditawarkan cukup ringan.

Selain syarat dan angguhan yang mudah, proses dalam pencairan dana pun mudah. Peraturan sebelum dan sesaat pandemi dalam pencairan produk kreasi ini tidak mengalami perubahan, hanya saja pihak perusahaan lebih selektif dalam menganalisa kelayakan usaha untuk menentukkan besarnya pinjaman. Sedangkan untuk pengguna produk kreasi pada masa pandemi mendapatkan keringanan dalam pembayaran angsuran selama 3 bulan. Hal 
ini dapat memudahkan sektor UKM dalam permodalan untuk bangkit dari keterpurukan terutama pada masa karantina ini dimana beberapa usaha baik UKM ataupun usaha besar mengalami kerugian bahkan terpaksa untuk berhenti. Masa Pandemi ini membuat sektor kecil menengah berupaya agar tidak jatuh dengan menambah modal untuk perputaran dana karena sedikitnya pemasukan dana dan pemenuhan kewajiban usaha menjadi terhambat. Usaha mikro kecil menengah membutuhkan produk perkreditan dengan bunga rendah untuk mengembangkan usaha yang sudah dijalankan. Oleh karena itu, Produk Kreasi yang dikembangkan oleh PT. Pegadaian (Persero) ini dapat membantu perkembangan Usaha Kecil Menengah terutama pada masyarakat Kota Probolinggo.

\section{METODE PENELITIAN}

Jenis penelitian ini adalah penelitian kualitatif. Menurut Straus dan Corbin dalam Sujarweni (2015: 211) "Yang dimaksud dengan penelitian kualitatif adalah jenis penelitian yang menghasilkan penemuan-penemuan yang tidak dapat dicapai atau diperoleh dengan menggunakan prosedur-prosedur statistic atau cara lain dari kuantifikasi (pengukuran). Penelitian kualitatif secara umum dapat digunakan untuk penelitian tentang kehidupan, masyarakat, sejarah, tingkah laku, fungsionalisme organisasi, aktivitas sosial dan lainnya”. Pendekatan kualitatif fenomenologi adalah penelitian yang menggali suatu data untuk menemukan makna hal - hal yang mendasar dari esensi suatu fenomena, realitas, atau pengalaman yang dialami objek. "Fenomenologi" kadang sering digunakan sebagai prespektif filosofi dan juga digunakan sebagai pendektan dalam metode kualitatif. Fenomenologi memiliki riwayat yang cukup panjang dalam penelitian sosial termasuk psikologi sosiologi dan pekerjaan sosial.

Kemudian sebagai data pendukung peneliti menggunakan penelitian kuantitatif. Menurut Sugiyono (2019: 16) "Metode penelitian kuantitatif dapat diartikan sebagai metode penelitian yang berlandaskan pada filsafat positivisme, digunakan untuk meneliti pada populasi atau sampel tertentu, pengumpulan data menggunakan instrumen penelitian, analisis data bersifat kuantitatif atau statistik, dengan tujuan untuk menguji hipotesis yang telah ditetapkan”. Penelitian kuantitatif digunakan oleh peneliti sebagai pendukung dalam menganalisa dan meneliti topik yang telah di tentukkan oleh peneliti.

Teknik yang digunakan dalam menentukan informan penelitian ini dengan menggunakan Stratified Sampling, hal ini disebabkan karena informan yang akan diwawancarai memiliki tingkatan - tingkatan atau strata didalam golongannya. Menurut 
Sugiono (2019: 130), "Teknik ini digunakan bila populasi mempunyai anggota/unsur yang tidak homogen dan berstrata secara proporsional". Informan yaitu 10 pelaku usaha kecil menengah (UKM) yang menggunakan produk Mikro Kreasi Ultra Mikro.

\section{HASIL DAN PEMBAHASAN}

\section{Prosedur Kredit Angsuran Sistem Fidiusia (KREASI)}

Berdasarkan hasil wawancara dengan Bapak Supriadi, S.E selaku pemimpin muda PT. Pegadaian (Persero) cabang Kota Probolinggo menyatakan bahwa "Dalam melakukan kegiatan pencairan Kreasi ini diperlukan analisis lanjutan berbeda dengan gadai karena tingkat risikonya tinggi dibandingkan gadai. Sehingga setelah pengajuan atau proses harus dilakukan survey untuk mengetahui layak tidaknya usaha dan bukti. Setelah persayaratan surat yang lengkap baru akan kita cairkan". Berdasarkan hasil penjabaran di atas, maka secara ringkas prosedur kredit angsuran sistem fidusia (KREASI) sebagai berikut :

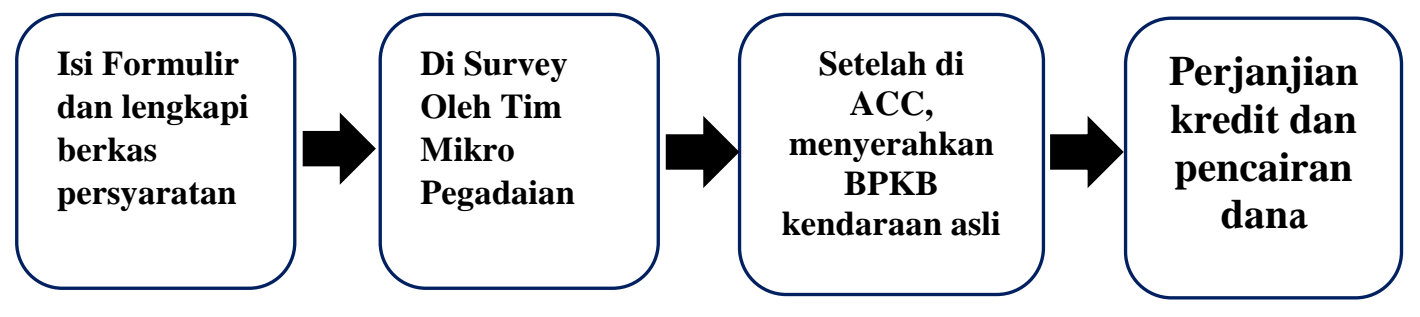

\section{Keunggulan Kredit Angsuran Sistem Fidusia (KREASI)}

Berdasarkan hasil wawancara dengan bapak Supriadi, S.E menyatakan bahwa "Keunggulan dari Kreasi ini selain hanya jaminan BPKB sehingga untuk usaha yang kenadaraan sebagai operasional menghasilkan masih bisa digunakan untuk menambah penghasilan". Hal ini juga didasarkan dari website resmi PT. Pegadaian (Persero) Kota Probolinggo, yaitu :

1) Prosedur pengajuan kredit sangat cepat dan mudah. Agunan cukup BPKB kendaraan bermotor;

2) Sewa modal (bunga pinjaman) relative murah dengan angsran tetap per bulan;

3) Dilayani diseluruh outlet Pegadaian dan aplikasi Pegadaian digital;

4) Proses kredit kurang lebih 3 hari dan dana dapat segera cair;

5) Pinjaman mulai dari 1 juta (tergantung agunan);

6) Jangka waktu cukup fleksibel mulai dari 3, 6, 12, 18, 24, hingga 36 bulan.

7) Pelunasan bisa dilakukan kapan saja 
Tabel Angsuran Kredit Angsuran Sistem Fidusia (KREASI)

1. Angsuran KREASI

\begin{tabular}{|c|c|c|c|c|}
\hline \multirow{2}{*}{$\begin{array}{c}\text { Jumlah } \\
\text { Pinjaman (Rp.) }\end{array}$} & \multicolumn{4}{|c|}{ Jangka Waktu Angsuran } \\
\hline & 12 Bulan & 18 Bulan & 24 Bulan & 36 Bulan \\
\hline 1.000 .000 & 95.833 & 68.056 & 54.167 & 40.278 \\
\hline 2.000 .000 & 191.667 & 136.111 & 108.333 & 80.556 \\
\hline 3.000 .000 & 287.500 & 204.167 & 162.500 & 120.833 \\
\hline 4.000 .000 & 383.333 & 272.222 & 216.667 & 161.111 \\
\hline 5.000 .000 & 479.167 & 340.278 & 270.833 & 201.389 \\
\hline 7.000 .000 & 670.833 & 476.389 & 379.167 & 281.944 \\
\hline 8.000 .000 & 766.667 & 524.600 & 413.400 & 322.222 \\
\hline 9.000 .000 & 862.500 & 590.200 & 465.100 & 362.500 \\
\hline 10.000 .000 & 958.333 & 680.556 & 541.667 & 402.778 \\
\hline 11.000.000 & 1.043 .167 & 737.611 & 584.833 & 432.056 \\
\hline 12.000 .000 & 1.138 .000 & 804.667 & 638.000 & 471.333 \\
\hline 15.000 .000 & 1.422 .500 & 1.005 .833 & 797.500 & 589.167 \\
\hline 20.000 .000 & 1.896 .667 & 1.341 .111 & 1.063 .333 & 785.556 \\
\hline 25.000 .000 & 2.370 .833 & 1.676 .389 & 1.329 .167 & 981.944 \\
\hline 30.000.000 & 2.845 .000 & 2.011 .667 & 1.595 .000 & 1.178 .333 \\
\hline 35.000 .000 & 3.319 .167 & 2.346 .944 & 1.860 .833 & 1.374 .722 \\
\hline 40.000.000 & 3.793 .333 & 2.268 .222 & 2.126 .667 & 1.571 .111 \\
\hline 45.000.000 & 4.267 .500 & 3.017 .500 & 2.392 .500 & 1.767 .500 \\
\hline \multirow{2}{*}{$\begin{array}{c}\text { Jumlah } \\
\text { Pinjaman (Rp.) }\end{array}$} & \multicolumn{4}{|c|}{ Jangka Waktu Angsuran } \\
\hline & 12 Bulan & 18 Bulan & 24 Bulan & 36 Bulan \\
\hline 50.000 .000 & 4.741 .667 & 3.352 .778 & 2.658 .333 & 1.963 .889 \\
\hline 51.000 .000 & 4.785 .000 & 3.368 .833 & 2.660 .500 & 1.952 .167 \\
\hline 70.000.000 & 6.568 .333 & 4.623 .889 & 3.651 .667 & 2.679 .444 \\
\hline 80.000.000 & 7.506 .667 & 4.137 .333 & 4.173 .333 & 3.062 .222 \\
\hline 90.000.000 & 8.445 .000 & 5.945 .000 & 4.695 .000 & 3.445 .000 \\
\hline 100.000 .000 & 9.383 .333 & 6.605 .556 & 5.216 .667 & 3.827 .778 \\
\hline 150.000 .000 & 14.000 .000 & 9.833 .333 & 7.750 .000 & 5.566 .666 \\
\hline 250.000 .000 & 23.333 .333 & 16.388 .889 & 12.916 .667 & 9.444 .444 \\
\hline 300.000.000 & 28.000 .000 & 19.666 .667 & 15.500 .000 & 11.333 .333 \\
\hline 350.000 .000 & 32.666 .667 & 22.944 .444 & 18.083 .333 & 13.222 .222 \\
\hline 400.000 .000 & 37.333 .333 & 26.222 .222 & 20.666 .667 & 12.333 .333 \\
\hline
\end{tabular}

Sumber : Data PT. Pegadaian (Perseo) Kota Probolinggo (2021)

\section{Jumlah Informan}


Dalam melakukan penelitian ini kehadiran informan adalah hal yang sangat penting bagi peneliti selain dari pengamatan secara langsung di lapangan, karena dengan adanya informan peneliti baru bisa mendapatkan informasi - informasi yang diinginkan dan tidak bisa peneliti prediksi dan tersembunyi pada saat melakukan pengamatan secara langsung. Denga adanya informan ini peneliti bisa dengan mudah menggali informasi - informasi yang diharapkan dapat membantu peneliti dalam menyelesaikan laporan ini. Data ini didasarkan pada hasil wawancara yang dilakukan oleh peneliti kepada pelaku usaha kecil dan menengah (UKM). Berikut adalah daftar informan yang bersedia memberi waktu dan pengalaman seputar apa yang ingin peneliti bahas.

Tabel Daftar Informan

\begin{tabular}{clccc}
\hline NO & Nama Informan & Jenis Usaha & $\begin{array}{c}\text { Jumlah } \\
\text { Pinjaman }\end{array}$ & $\begin{array}{c}\text { Jangka } \\
\text { Waktu }\end{array}$ \\
\hline $\mathbf{1}$ & $\begin{array}{l}\text { Ayu Pradita } \\
\text { Suryantini/Nanok }\end{array}$ & $\begin{array}{c}\text { Toko Sembako } \\
\text { + Kerupuk }\end{array}$ & Rp. 5.000.000 & 24 \\
$\mathbf{2}$ & Sri Asutik & Laundry & Rp. 5.000.000 & 24 \\
$\mathbf{3}$ & Siti Nurhartatik & Tailor & Rp. 5.000.000 & 18 \\
$\mathbf{4}$ & Murtila & Penjual Rujak & Rp. 6.000.000 & 18 \\
\hline $\mathbf{5 0}$ & Nama Informan & Jenis Usaha & $\begin{array}{c}\text { Jumlah } \\
\text { Pinjaman }\end{array}$ & Jangka \\
Waktu
\end{tabular}

\section{PEMBAHASAN}

Berdasarkan jumlah nasabah yang peneliti lakukan wawamcara berjumlah 10 orang informan yang melakukan pinjaman menggunakan produk Kreasi. Terdapat beberapa nasabah yang mengalami peningkatan pendapatan bersih dikarenakan pembiayaan yang didapat digunakan untuk nenambah stok barang atau menambah property pendukung usaha. Dan beberapa nasabah tidak mengalami peningkatan pendapatan bahkan penghasilannya menurun karena kondisi pandemi ini yang menjadi faktor utama. Berikut data nasabah yang mengalami peningkatan pendapatan dan tidak mengalami peningkatan pendapatan usaha. 


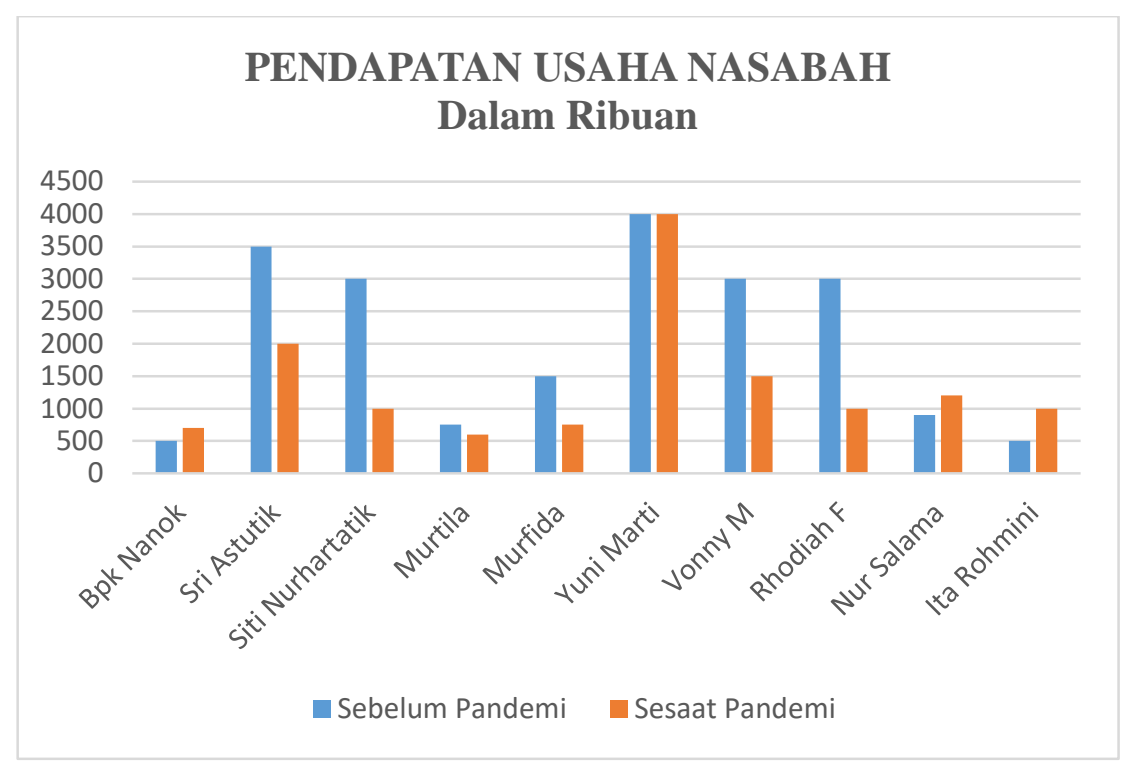

Berdasarkan dari hasil penelitian dan wawancara yang dilakukan secara langsung terhadap nasabah pengguna produk Kreasi terkhususkan produk Ultra Mikro yang disalurkan oleh PT. Pegadaian ditujukkan untuk pelaku usaha mikro. Sebagai data pendukung dalam menganalisa perkembangan atau pertumbuhan UKM di masa pandemi Covid-19 ini, peneliti mneyajikan perhitungan sebagai berikut :

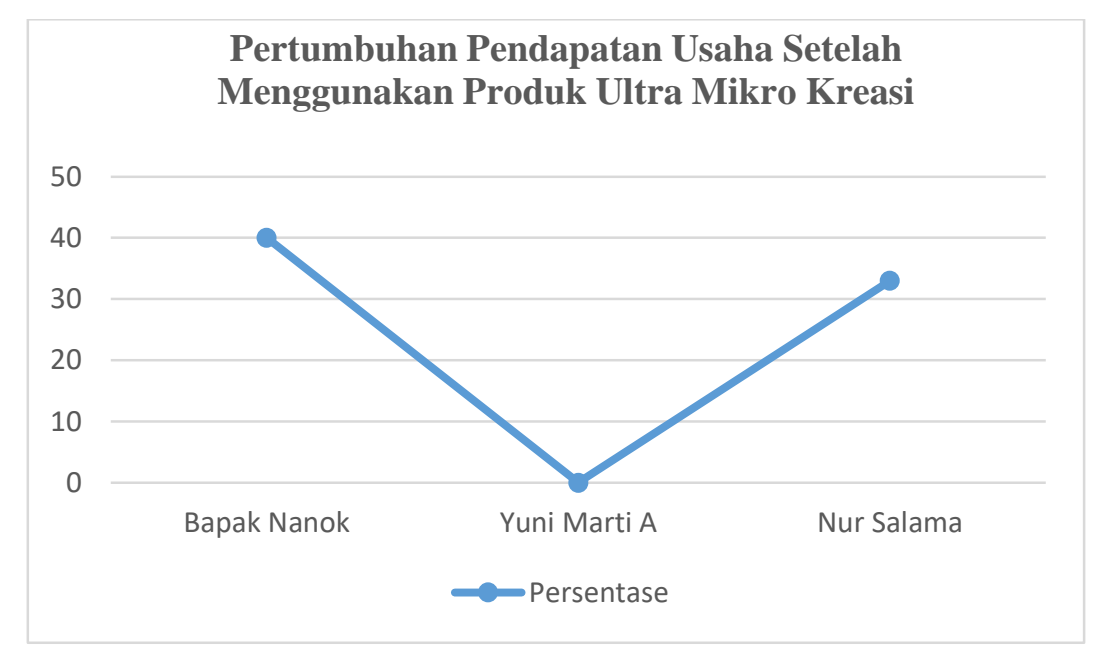

Berdasarkan grafik diatas menunjukkan bahwa nasabah produk Kreasi yang mengalami peningkatan pendapatan usaha sebanyak 2 orang dengan persentase positif yang menunjukkan bahwa usaha tersebut mengalami kenaikan pendapatan bersih antara $30 \%$ 40\% setiap bulan setelah menggunakan produk Ultra Mikro Kreasi. Berdasarkan hasil wawancara dengan ibu Ayu Pradita/Bapak Nanok dan ibu Nur Salama bahwa mereka 
menggunakan dana Ultra Mikro Kreasi ini tujuan menambah jenis usaha seperti ibu ayu yang awalya hanya memiliki usaha toko sembako, kini juga merambah ke usaha kerupuk.

Berdasarkan grafik diatas juga menunjukkan bahwa terdapat 1 nasabah yang memiliki presentase $0 \%$ dimana modal usaha digunakan untuk menambah media tumbuh jamur (BagLog). Dalam perkembangannya di masa pandemi ini usaha jamur tersebut mengalami penurunan minat beli konsumen, meskipun terdapat beberapa pengurangan pesanan dari rumah makan, tetapi tidak mengurangi penjualan karena ibu Yuni juga mempromosikannya lewat media sosial.

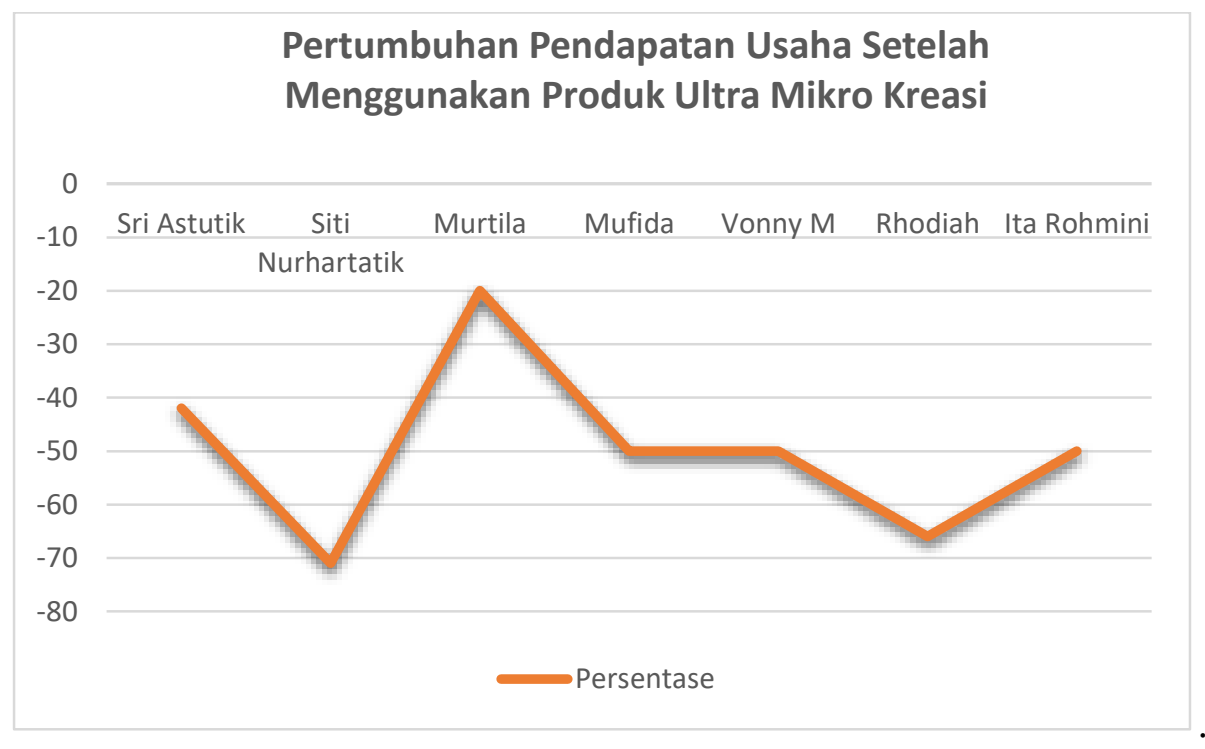

Berdasarkan hasil wawancara dalam diagram di atas menunjukkan bahwa dari 10 nasabah pengguna Ultra mikro Keasi, terdapat 7 nasabah pengguna produk Ultra Mikro Kreasi dimana hasil dari persentase bernilai minus (-). Hal ini memiliki makna bahwa 7 nasabah ini tidak mengalami peningkatan pendapatan nasabah karena dari hasil pembiayaan yang didapat digunakan untuk menambah jumlah produk tanpa membuat variasi usaha baru. Salah satu penyebabnya adalah turunnya minat beli konsumen dikarenakan masa pandemi Covid-19 ini.

Hal ini di karenakan keadaan pandemi yang melanda sehingga nasabah hanya dapat bertahan untuk menjalankan usaha tersebut. Tambahan modal yang di dapatkan digunakan untuk menambah propeti seperti mesin dan juga stock barang tetapi tidak menambah usaha lain sehingga pendapatan yang di dapatkan tidak mengalami peningkatan. Hal ini juga terjadi akibat jenis usaha yang dimiliki memiliki kaitan dengan anak sekolah atau perkantoran seperti laundry. 


\section{Strategi Bagi Usaha Kecil dan Menengah (UKM) Di Masa Pandemi Covid-19}

Pandemi Covid-19 yang terjadi berdampak pada perekonomian terutama terhadap UKM. Pembatasan - pembatasan sosial yang dilakukan guna mencegah penyebaran juga membuat pelaku usaha konvensional atau UMKM harus beradaptasi terhadap keadaan yang sedang terjadi. Strategi yang dapat dilakukan oleh UMKM untuk bertahan pada masa pandemi Covid-19 ini, sebagai berikut :

1. Mempelajari Digital Marketing sebagai implementasi pemanfaatan digital dalam melakukan promosi melalui media sosial.

2. Memperluas pengetahuan mengenai era globalisasi dan teknologi untuk memperkuat sumber daya manusia yang ada.

3. Berinovasi secara kreatif dalam melakukan promosi untuk menarik minat konsumen membeli produk yang ditawarkan.

4. Meningkatkan pelayanan kepada konsumen seperti adanya sistem Delivery Order sehingga dapat memudahkan pelanggan dalam mendapatkan kebutuhannya.

5. Mengikuti seminar atau pelatihan khusus untuk UMKM agar dapat menambah wawasan dan relasi serta ilmu yang dapat diterapkan dalam usahanya terutama mempertahankan usaha pada masa pandemi Covid-19 ini.

\section{KESIMPULAN}

Berdasarkan dari hasil penelitian yang dilakukan terhadap pelaku Usaha Kecil dan Menengah (UKM) dalam perkembangan usahanya seluruh informan menyatakan bahwa usahanya mengalami perkembangan dengan adanya modal tambahan dari menggunakan produk Kreasi. Hal ini dikarenakan setelah mendapatkan tambahan modal ini, pelaku usaha menambah stock barang juga menambah properti seperti mesin pendukung usahanya dan juga menambah jenis usaha. Sehingga para pelaku usaha merasa terbantu dengan adanya produk Kreasi ini. Informan juga merasa bahwa produk Kreasi ini memiliki tingkat bunga yang rendah sehingga dalam pembayaran kredit tidak memberatkan para pelaku Usaha Kecil Menengah (UKM) untuk bertahan di masa pandemi covid-19 ini.

\section{UCAPAN TERIMA KASIH}

Penulis menyadari bahwa penelitian ini tidak dapat terselesaikan tanpa adanya bimbingan dan dukungan dari berbagai pihak di antaranya Prof. Dr. Ir. H. R. Abdul Haris, M.M. selaku Rektor Universitas Panca Marga Probolinggo; IbuKhusnik Hudzafidah, S.E., 
M. Si. Selaku Dekan Fakultas Ekonomi Universitas Panca Marga Probolinggo; yang telah memberikan arahan dan bimbingan serta masukan guna kesempurnaan penelitian dan penlisan skripsi ini; Bapak Supriadi, S.E selaku kepala cabang muda PT. Pegadaian (Persero) Kota Probolinggo yang telah menyediakan waktu dan tempat untuk melakukan penelitian demi terwujudnya penelitian yang baik dan dapat bermanfaat bagi masyarakat.

\section{DAFTAR PUSTAKA}

Ayodya, Wulan. 2020. UMKM 4.0 (Strategi UMKM Memasuki Era Digital 4.0). Jakarta : PT. Elex Media Komputindo.

Hidayatullah \& Sukiman. 2019. STUDI KOMPARATIF PENDAPATAN PRODUK KREDIT CEPAT AMAN (KCA) DENGAN PRODUK KREDIT ANGSURAN SISTEM FIDUSIA (KREASI) DI PT. PEGADAIAN CABANG SINJAI (ANALISIS TINJAUAN SYARIAH). JURNAL LEMBAGA KEUNGAN, EKONOMI, DAN BISNIS ISLAM Volume 1, No. 1. http://journal.asy-syarikah.iaims.ac.id. p-ISSN: 2656-6117

PT. Pegadaian Annual Report. 2016. ANNUAL REPORT LAPORAN TAHUNAN PERUM PEGADAIAN 2016. Jakarta: Sinar Grafika.

Sugiyono. 2019. METODE PENELITIAN KUANTITATIF KUALITATIF DAN R\&D. Bandung: Alfabeta

Sujarweni, V. Wiratman. 2015. METODOLOGI PENELITIAN - BISNIS \& EKONOMI. Yogyakarta: Pustakabarupress

Umami, Fadli, dkk. 2020. Eksekusi Jaminan Fidusia Produk Kreasi Pada Pegadaian Cabang Kosambi Tangerang. Jurnal Notarius, Volume 13 No. 1. E-ISSN: 2686-2425 ISSN: 2086-1702

(C) 2021 by authors. Content on this article is licensed under a Creative Commons Attribution 4.0 International license. (http://creativecommons.org/licenses/by/4.0/). 